\title{
A SINTAXE DOS PRONOMINAIS ÁTONOS EM PERSPECTIVA: UM EXAME VARIACIONISTA DO FENÔMENO DE CLITICIZAÇÃO EM GÊNEROS TEXTUAIS DO PORTUGUÊS DO BRASIL DO SÉCULO XX ${ }^{1}$
}

Daniely Cassimiro de Oliveira Santos ${ }^{2}$

s.cassimiro@uol.com.br

RESUMO: Esta investigaçāo pretende determinar o estatuto da ordem dos cliticos pronominais na modalidade escrita do Português do Brasil (PB) do século XX. Para tanto, analisam-se contextos constituidos de lexias verbais simples, considerados como ambientes proficuos para análise da ordem dos pronomes em próclise e ênclise. Este estudo, por meio dos postulados acerca dos principais fatores motivadores da ordem pronominal no PB escrito, visa a contribuir para as pesquisas linguísticas sobre o mesmo tema.

Palavras-chave: clítico pronominal; Sociolinguistica; variação

\section{INTRODUÇĀO}

Este trabalho tem o propósito de descrever o comportamento da ordem dos pronomes átonos verificada na modalidade escrita do português brasileiro no decorrer de todo o século XX, no que concerne ao dominio de lexias verbais sim-

1 O trabalho, aqui apresentado, dispõe do apoio financeiro e intelectual da Fundaçāo Carlos Chagas Filho de Amparo à Pesquisa do Estado do Rio de Janeiro concernente ao Programa Bolsa Nota 10 (Mestrado) da FAPERJ.

2 Mestranda da UFRJ 
ples, isto é, estruturas oracionais constituídas de uma única forma verbal.

No que respeita à fundamentação teórico-metodológica, esta investigação, de caráter variacionista, concebe-se sob a égide dos postulados da Sociolinguística Laboviana ou Teoria da Variação e Mudança (WEINREICH, LABOV e HERZOG, 1968; LABOV 1972; 1994). Com base nessa fundamentação, estuda-se especificamente o parâmetro de precedência proposto por Klavans (1985), que estabelece a possibilidade de o clítico pronominal ocorrer antes ou depois de seu hospedeiro sintático, isto é, o verbo (como em 'me dá' ou 'dá-me'). A conjugação dessas orientações investigativas favorece a adequação descritiva e explicativa que se pretende alcançar no desenvolvimento da pesquisa.

Para o tratamento da modalidade escrita, recorre-se a textos jornalísticos e literários, de modo a observar a norma linguística efetivamente usada na imprensa e aquela empregada por escritores brasileiros, a qual constitui a base da descrição gramatical tradicional (CUNHA e CINTRA, 2001, p. 309318; LIMA, 2006, p. 416-420). A análise dos dados coletados no material em questão permitiu identificar as variāveis linguísticas e extralinguísticas responsáveis pelo condicionamento da ordem dos âtonos pronominais.

\section{FundamentaÇão teórica}

Pautando-se no preceito sociolinguístico que autentica a língua como um sistema, por excelência, de variaçāo intrinseca não arbitrária (WEINREICH, LABOV e HERZOG, 1968), o presente estudo concebe a ordem dos clíticos pronominais como um fenômeno de legítima variação.

Parte-se do pressuposto de que o comportamento variável dos pronomes átonos - que constitui a variável dependente - é motivado por fatores internos e externos à própria língua, ou seja, as variáveis independentes. Em outras palavras, 
condicionamentos linguísticos (estruturais) e extralinguisticos (sociais) presidem a regra variável, consoante o que ficou conhecido, na Teoria da Variação e Mudança, como o problema das restrições" (WEINREICH, LABOV e HERZOG, 1968; LABOV 1972). Desse modo, considerando-se próclise ('me fala') e ênclise ('fala-me') como fatores constitutivos da variável dependente, investigam-se os grupos de fatores - as restrições - possivelmente responsáveis pelo condicionamento do fenômeno em variação.

No que se refere à trajetória das variantes da ordem dos clíticos pronominais no decorrer do século $\mathrm{XX}$, o trabalho adota, ainda, a premissa sociolinguística de que toda mudança pressupõe variaçāo, embora nem toda variação concorra em mudança linguística (WEINREICH, LABOV e HERZOG, 1968; LABOV 1994).

Conjugado ao aporte variacionista, o estudo lança mão de um dos parâmetros de cliticização proposto por Klavans (1985), o chamado 'parâmetro da precedência' Partindo do pressuposto de que as formas clíticas (partículas átonas) ocorrem ligadas a um elemento sintático específico (seu hospedeiro), a autora propōe que as línguas do mundo podem ser caracterizadas quanto à posição dos clíticos - antes ou depois em relação a esse elemento sintático. Tendo os pronomes átonos do português o verbo como hospedeiro sintático, interessa à investigação observar os fatores que determinam a ligação entre o clítico e o verbo nas posições pré-verbal ('se estuda') e pós-verbal ('estuda-se').

\section{REVISÃO BIBLIOGRÁFICA}

Torna-se conveniente, nesta seção, apresentar brevemente alguns trabalhos sobre o tema da cliticização pronominal cujos postulados orientam e fundamentam o presente estudo. Destacam-se, aqui, duas pesquisas que também investigaram dados jornalísticos ou literários: Vieira (2002) e Schei (2003). 
Vieira (2002) analisou o fenômeno da colocação pronominal nas variedades brasileira, européia e moçambicana do português, nas modalidades oral e escrita, em gêneros jornalísticos diversos. Com base na observação de pronominais átonos em enunciados constituídos de lexias verbais simples (estruturas com uma só forma verbal) e de complexos verbais (estruturas com mais de uma forma verbal), o estudo desenvolveu uma investigação não só morfossintática, mas também prosódica.

A respeito da distribuição de próclise, mesóclise e ênclise, atestou-se que, nas modalidades oral e escrita, a variante mesoclítica, em ambiente de lexias verbais simples, se mostrou em flagrante desuso nas variedades portuguesas do Brasil (PB), de Portugal (PP) e de Moçambique (PM). Ademais, constatou-se que a ordem proclítica é de ocorrência expressiva no PB, nos diversos contextos sintáticos observados na modalidade oral. No âmbito das variedades européia e moçambicana, a variante enclítica é a mais característica. em ambas as modalidades, quando se trata de início absoluto de oração; nos demais contextos, a próclise, obedecendo a condicionamentos estruturais, passa a ser a opção preferencial. No que respeita aos complexos verbais, constataram-se maiores índices da variante intra-complexo verbal ('pode me dar') nas três variedades analisadas. A propósito do estudo prosódico, estabelecido entre PB e PP observou-se que o pronome átono no $\mathrm{PB}$ apresenta, quanto à duração e à intensidade, as mesmas configuraçōes de uma sílaba pretônica vocabular. No que concerne ao $\mathrm{PP}$, os átonos pronominais assumem as características de qualquer sílaba átona vocabular, não importando o caráter postônico ou pretônico.

Igualmente tendo como foco a colocação dos pronomes átonos, Schei (2003) dedica-se à análise de textos literários, elegendo, para tanto, romances contemporâneos de autores brasileiros e portugueses. Em linhas gerais, o estudo verifica que a lingua idealizada nos compêndios gramaticais brasilei- 
ros toma como referência, quanto à ordem dos clíticos, os padrões averiguados na literatura portuguesa.

É oportuno registrar, ainda, que, segundo Schei (2003), os possiveis fatores envolvidos no condicionamento da ordem são a forma verbal com que o clítico se relaciona, o tipo de átono pronominal e a semântica com que as partículas átonas são concebidas. A autora, apesar de não realizar uma pesquisa histórica, lembra que, até o século XI, a colocação prototípica no PP era a próclise; contudo, nos séculos posteriores, a norma enclítica, que passa a ser a opção preferencial, torna-se fator de identidade da variedade européia. Assim sendo, Schei (2003), ao constatar altos índices de próclise em todos os contextos sintáticos do português do Brasil, admite que a norma de uso verificada o aproxima da norma atribuída ao PP do século XI.

Mediante a apresentação de dois dos principais trabalhos que motivaram a presente investigação, no que tange à colocação dos pronomes átonos em textos jornalísticos e literários, expõe-se, a seguir, a metodologia adotada neste estudo.

\section{Metodologia}

No que concerne às fontes para o estudo do evento variável, faz-se saber que o corpus referente ao dominio jornalístico é constituído de textos brasileiros dos gêneros anúncio, editorial e notícia, publicados no século $\mathrm{XX}$ e disponibilizados pelo banco de dados do Projeto Varport, que se ocupa da análise contrastiva das variedades brasileira e européia da língua portuguesa. Esse banco de dados segmenta o século XX em quatro periodos de aproximadamente 25 anos cada: fase 1 (de 1901 a 1924); fase 2 (de 1925 a 1949); fase 3 (de 1950 a 1974); fase 4 (de 1975 a 2000) ${ }^{3}$. Quanto ao domí-

3 Faz-se saber que a distribuição das fases, assim estabelecidas ao longo do século XX, no corpus Varport. decorre do principio sociolinguístico de que o estudo diacrônico leva em consideração um intervalo aproximado de 20 a 25 
nio literário, o presente trabalho, privilegiando a época de publicação nos mesmos períodos contemplados no corpus Varport, vale-se de $\operatorname{contos}^{4}$ contemporâneos aos textos jornalísticos, o que promove uma análise contrastiva do fenômeno de colocação pronominal nos dois domínios estudados.

A constituição dos corpora contribuiu para a investigação da ordem dos pronomes átonos no sentido de que eles se apresentaram como ambientes apropriados para a compreensão das variáveis linguísticas e extralinguísticas que influenciam a ocorrência do evento variável.

A propósito do tratamento estatístico dos casos de colocação pronominal extraídos dos textos, utilizou-se, como instrumental, o pacote de programas GOLDVARB, recurso que disponibiliza as seguintes informações: (a) o indice de aplicabilidade da regra variável da ordem dos clíticos pronominais, isto é, a distribuição geral das variantes proclítica e enclítica; (b) a frequência, os valores absolutos e percentuais e os pesos relativos ${ }^{5}$ de cada variante estudada; (c) as variáveis linguísticas e extralinguísticas relevantes e não relevantes ao condicionamento do fenômeno em análise; (d) o influxo, isto é, o cruzamento entre grupos de fatores.

Ressalte-se que as ocorrências de clíticos pronominais provenientes dos corpora estudados foram tratadas em função das variáveis estabelecidas na análise sociolinguística, discriminadas em seguida:

anos (MOLLICA e BRAGA. 2003). Ademais, o ano referente ao início bem como ao fim de cada fase determinada diz respeito à disponibilidade de material necessário para a constituição do corpus.

5 Entende-se por peso relativo o valor de aplicaçāo da variante analisada em relação a determinado fator. Em outras palavras, trata-se do valor de probabilidade de ocorrência da variante em um dado contexto, no confronto com todos os demais. 
(a) variável dependente ${ }^{6}$ : estipulada a partir dos fatores próclise ("O esforço não se limitaria ao campo" [EB-92-Je-006] $]^{7}$ ) e ênclise ("Acabou-se a necessidade de trabalho e paciência” [E-B-92-Ja-032]).

(b) variáveis independentes de caráter extralinguístico: consideraram-se os gêneros textuais (anúncio, editorial, notícia e conto), a época de publicação dos textos (fase 1, 2, 3 ou 4) e, especificamente para o dominio literário, os autores ${ }^{8}$, tendo sido selecionados escritores eleitos por um crítico literário como representativos dos períodos em questão.

(c) variáveis independentes de caráter linguístico: para essa categoria, controlaram-se os grupos de fatores tipo de oração, possivel elemento atrator do clítico, distância entre o grupo verbo-clítico ou clítico-verbo e um elemento atrator, tempos e modos verbais, tipo de clítico e tonicidade das formas verbais.

6 Não se considerou na análise computacional variacionista, cujo modelo matemático só contempla variáveis binárias, a variante mesoclítica. Isto porque essa variante só ocorre com as formas verbais do futuro, o que nāo segue a premissa de que as variantes devem, além de ter o mesmo significado, ocorrer no mesmo contexto.

7 De modo a conhecer o significado de cada código nas notações que identificam os dados no corpus Varport, deve-se considerar ' $E$ ' como modalidade escrita; ' $\mathrm{B}$ ' como Brasil; o número ' 9 ' como século $\mathrm{XX}$ : o número posposto ao 9 como referència a uma das quatro fases do mesmo século - neste caso particular, a fase exemplificada é a segunda -: ' $J$ ' como texto jornalistico: ' $e$ ' como género editorial, podendo aparecer nesta posiçāo as letras minúsculas 'a' e 'n', representando, respectivamente, os géneros anúncio e noticia: e, os três dígitos finais como o número de localização do texto no corpus. Esclarece-se, ainda, que os dados são transcritos neste trabalho da mesma forma como são verificados no banco de dados.

8 Optou-se por investigar textos de escritores consagrados pela tradiçāo literária, tendo em vista o desenvolvimento de estudos futuros em que se pretende atestar em que medida as gramáticas brasileiras se inspiram no fazer dos grandes autores da lingua portuguesa. 


\section{Resultados}

Consoante a análise dos dados, verificou-se que as ocorrências das variantes no corpus jornalístico se distribuem numa proporção de 56\% para a colocação pré-verbal e de 44\% para a pós-verbal, a depender do contexto morfossintático em que se observam os clíticos pronominais. No dominio literário, atestou-se um indice de $51 \%$ para a variante pré-verbal em face de $49 \%$ da variante pós-verbal.

Levando em consideração o comportamento particular dos pronomes átonos em contextos de início absoluto de oraçāo ("Emprega-se externamente para combater o reumatismo." [E-B-91-Ja-001]), em que tradicionalmente se prescreve a variante pós-verbal, decidiu-se separar esses ambientes daqueles em que os clíticos pronominais não se encontram em início de oração, mas antecedidos por algum elemento, que pode funcionar como um possivel atrator ("O governo não se mostra muito preocupado com os arroubos oposicionistas." [E-B-93-Je-005]). Isto porque o estudo pretendeu estabelecer uma análise da manifestação de próclise a partir da presença de um elemento proclisador, o que não seria possível em contextos de início de oração, devido à ausência de tais elementos.

\subsection{DistribuiçĀo das VARIANTES PROClítica E ENClítica}

\subsubsection{EM FUNÇĀO DOS CONTEXTOS ORACIONAIS}

Apresenta-se, a seguir, a frequência percentual de realização das variantes proclítica e enclítica em início absoluto de oração e nos contextos em que se observam os possiveis elementos proclisadores. 


\subsubsection{CONTEXTO DE INÍCIO ABSOLUTO DE ORAÇĀO (SEM ELEMENTOS PROCLISADORES)}

Observem-se os valores percentuais subsequentes relativos à ocorrência de próclise e ênclise em contexto de início absoluto, verificados nos domínios jornalístico e literário.

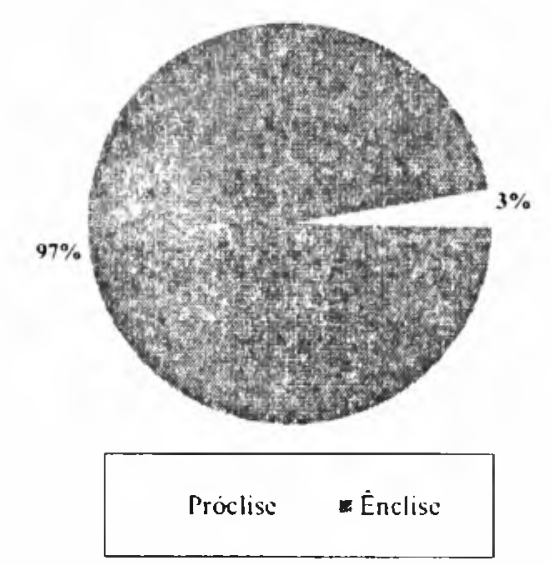

Figura 1: Dominio jornalistico

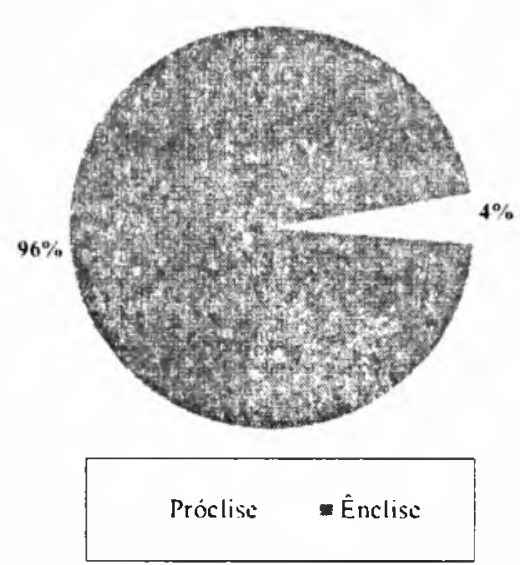

Figura 2: Domínio literário

As Figuras 1 e 2 indicam que, em início absoluto de oração, os índices percentuais de ènclise sobrepujam expressivamente os de próclise nos domínios jornalístico e literário, o que demonstra ser essa variante a opção preferencial do contexto morfossintático em questão.

\subsubsection{ConTEXTOS CONSTITUÍdOS DE ELEMENTOS "PROCLISAdORE"}

Os valores percentuais seguintes dizem respeito à ocorrência de próclise e ênclise em contextos em que se verificam elementos que poderiam atuar como atratores do pronome átono, previstos ou não na tradição gramatical (por exemplo, partículas negativas, advérbios, conjunções subordinativas, entre outros), considerando-se os dominios jornalístico e literário. 


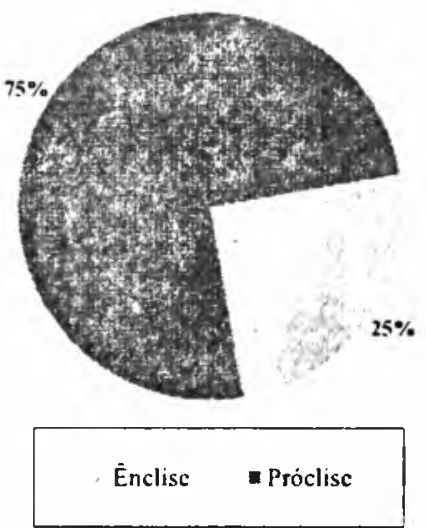

Figura 3: Dominio jornalistico

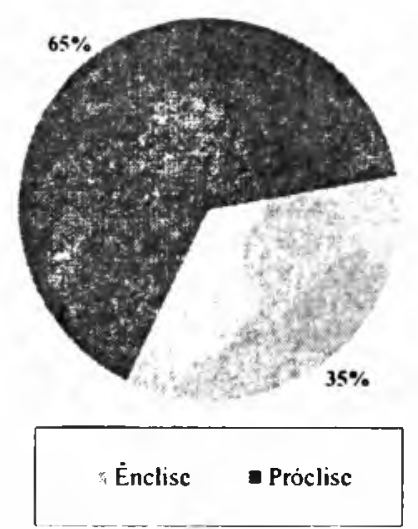

Figura 4: Dominio literário

As Figuras 3 e 4 permitem observar que a presença de elementos anteriores ao 'clítico e ao verbo' faz alterar radicalmente o comportamento verificado no contexto em que $o$ verbo e o clítico' se encontram em início absoluto de oração. Em ambos os domínios estudados, os percentuais de próclise passam a ser superiores aos de ênclise.

\subsection{ANÁLISE DOS DADOS A PARTIR DAS VARIÁVEIS EXTRALINGUÚSTICAS}

Expõem-se, a seguir, os índices percentuais relativos à época de publicação e ao gênero textual, considerando-se os contextos com a presença de elementos proclisadores. Os ambientes com os verbos e os pronomes em início absoluto de oração, em que se verificam dados de ênclise, não apresentaram, nos dois domínios estudados, diferença do comportamento já descrito ao longo das fases controladas.

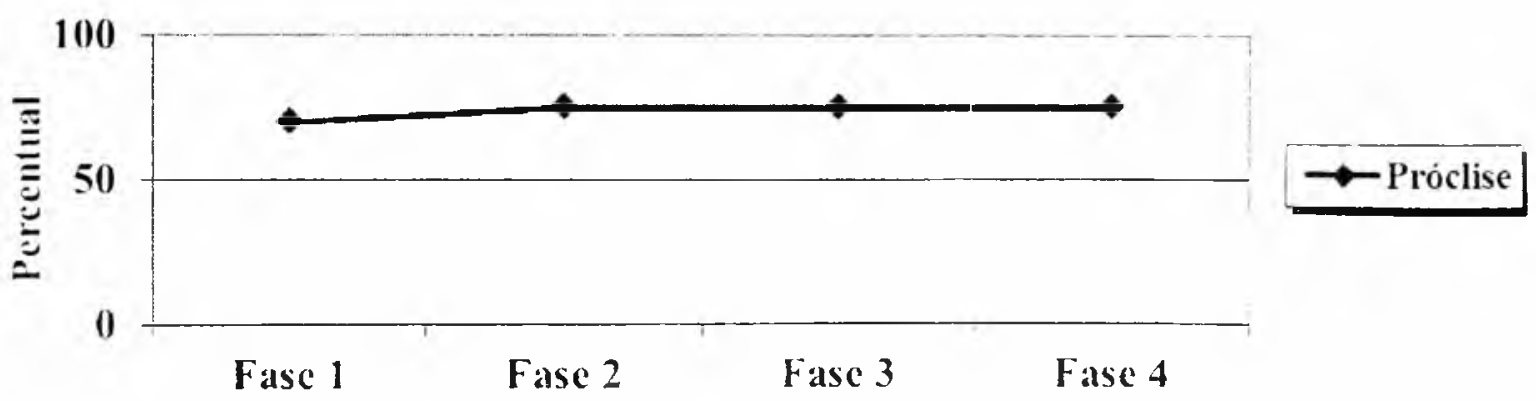

Figura 5: Distribuição da variante pré-verbal segundo a época de publicação dos textos jornalísticos nos contextos com elementos proclisadores 
Com base nos percentuais de próclise em cada fase, nos contextos em que não se consideraram os pronomes nos chamados inícios absolutos de oração, constataramse, no corpus jornalístico, altos e semelhantes índices de próclise (entre 70 e $80 \%$ ), tendo sido registrado, apenas, um ligeiro aumento na passagem da primeira para a segunda fase do século XX.

Observe-se, a seguir, o comportamento diacrônico dos dados de próclise no domínio literário.

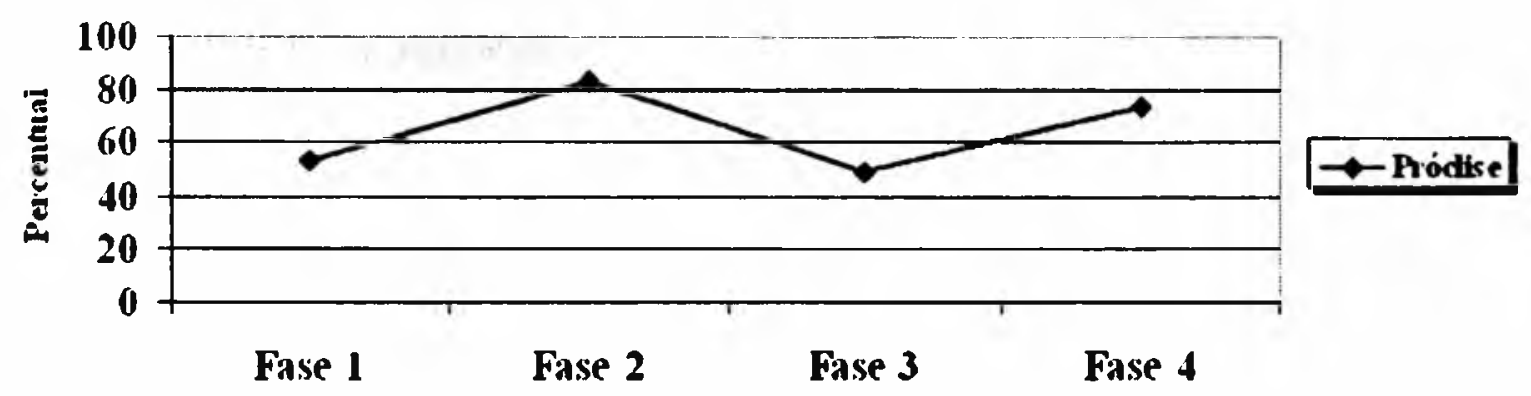

Figura 6: Distribuiçāo da variante pré-verbal segundo a época de publicação dos textos literários nos contextos com elementos proclisadores

No que respeita ao domínio literário, o gráfico relativo à época de publicação revela uma manifestação instável da próclise ao longo do século investigado, com indices mais elevados nas fases 2 e 4 . Supõe-se, a esse respeito, que a influência das tendências literárias de cada época, bem como a estilística dos diferentes autores podem colaborar para a diferença de comportamento dos dados em cada periodo. Com a continuidade da pesquisa, essas hipóteses serão devidamente investigadas.

A propósito dos gêneros textuais analisados, apresentam-se, a seguir, as frequências de próclise, considerando-se todos os contextos observados. 


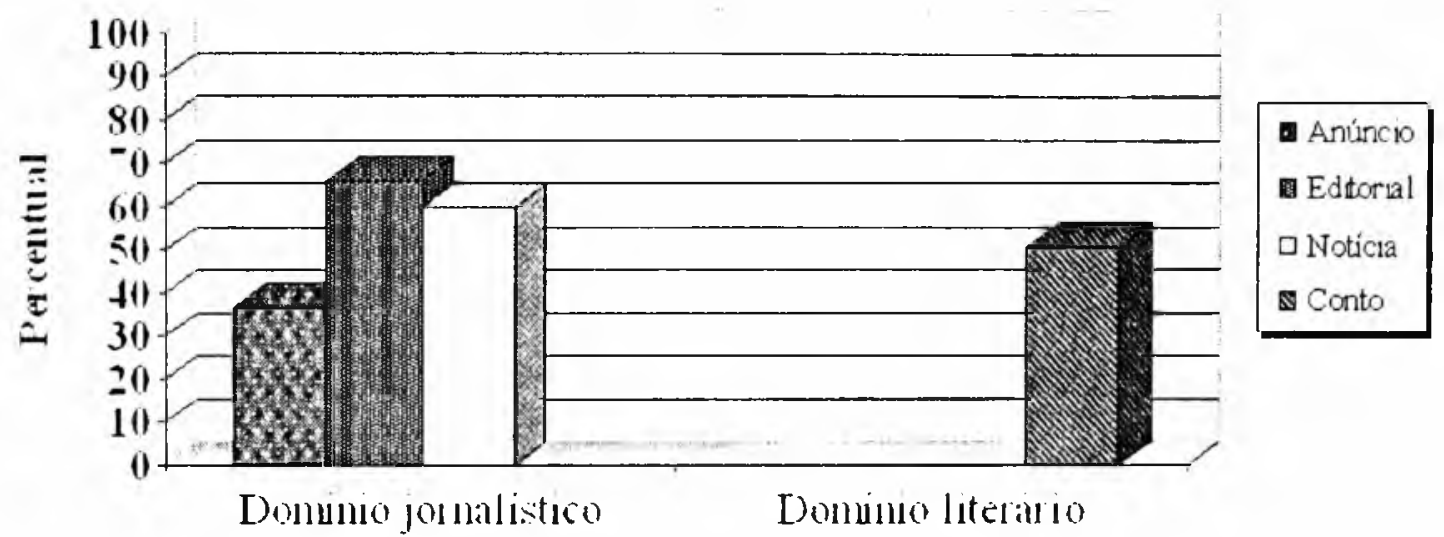

Figura 7: Distribuição de próclise em face do gênero textual

No que tange à variável extralinguística gênero textual, observa-se que, excetuando-se os anúncios, todos os gêneros contemplados registram índices da variante pré-verbal a partir de 50\%. Analisando os dados coletados em anúncios, verifica-se que o comportamento particular dos cliticos nesses textos está relacionado ao fato de esse gênero textual apresentar grande quantidade dos chamados inícios absolutos de oração, decisivos à ocorrência de ênclise.

\subsection{ANÁlise dos DADOS a PARTIR dAS VARIÁVEIS LINGUÍSTICAS}

Apresenta-se, doravante, a atuação dos fatores constitutivos de cada variável linguística que foi considerada estatisticamente relevante, conforme a seleção efetuada pelo programa computacional utilizado, em relação à variante pré-verbal.

\subsubsection{AplicaÇĀo da PRÓClise SEgundo os POSSÍVEIS ELEMENTOS PROCLISADORES}

As representaçōes gráficas a seguir apresentam os pesos relativos obtidos para a variante proclítica em face dos possíveis elementos atratores do pronome clítico nos domínios jornalístico e literário. 


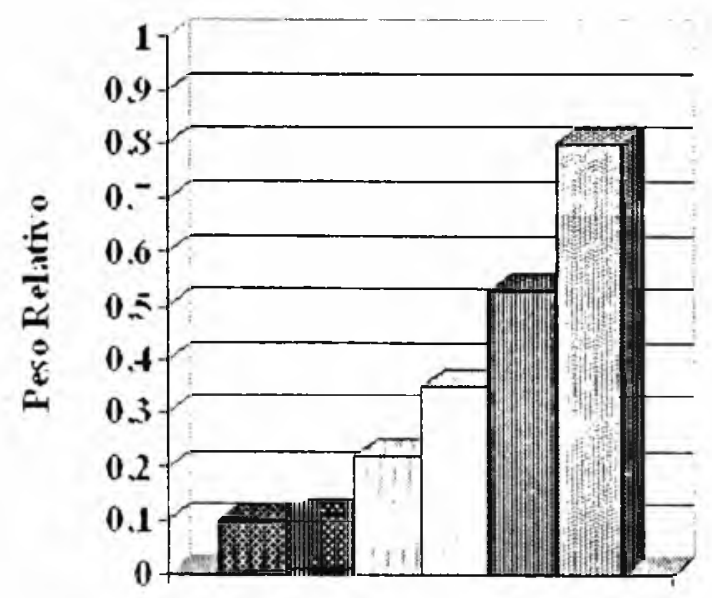

Figura 8: Dominio jornalistico

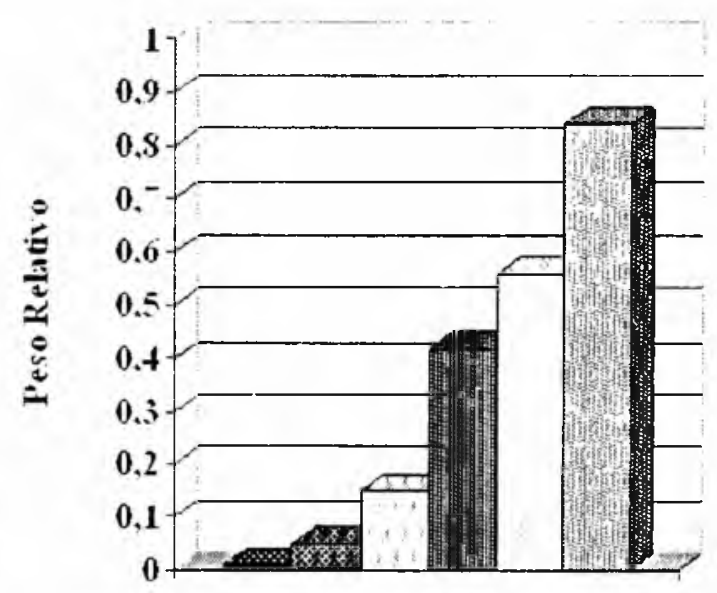

Figura 9: Dominio literário
Cony coosdenation
SAdi-Loc. adtenbial
[ ] SN Sujeito
$\square$ F'rep. 'prar'. 'en', 'de', 'pror', 'sent, 'a'

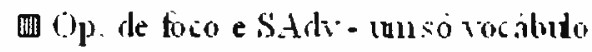

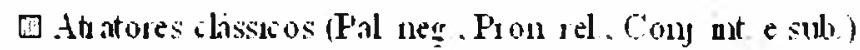

Nota-se que, em ambos os dominios, os chamados atratores clássicos promovem efetivamente, em primeira instância, a anteposição dos clíticos pronominais ao verbo. A propósito das preposições, que não são tradicionalmente consideradas como atratores, observa-se seu favorecimento a próclise em segunda instância no contexto literário; no contexto jornalístico, elas aparecem em terceira instância e não constituem elementos motivadores da próclise. Similar é o fenômeno verificado com os operadores de foco e sintagmas adverbiais de um só vocábulo ${ }^{8}$ uma vez que tais itens se apresentam em segunda posição de maior atração do clítico pronominal no corpus jornalístico, enquanto, no corpus literário, aparecem em terceira posição e não favorecem a próclise. De outro lado, o comportamento das conjunções coordenativas, das locuções adverbiais e dos sujeitos, nos dois domínios, é compativel com o que propõe a tradição gramatical, visto que esses elementos se revelam como desfavorecedores da variante pré-verbal. 


\subsubsection{APLICAÇÃo da PRÓCLISE SEGUNDO A VARIÁVEL TEMPO E MODO VERBAIS}

Nesta seção, expõem-se os valores de aplicação da próclise mediante a variável tempo e modo verbais nos contextos jornalístico e literário.

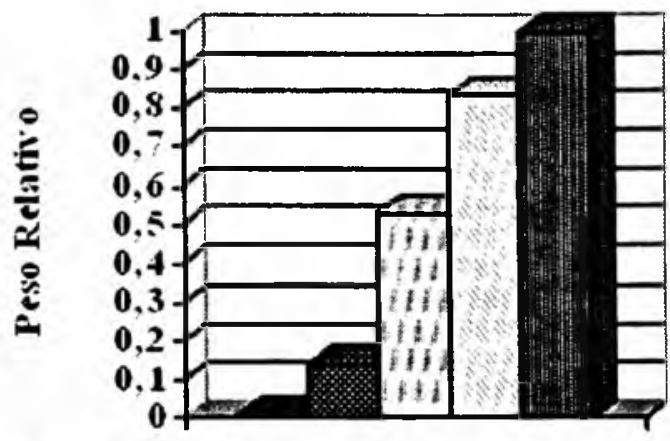

-imperativo

Dinfinitivo Genundio

口Presente e Pretéritos do Indicativo

口Presente. Pret imp) e Futmro do Subjuntivo

国 Futuros do Indicativo

Figura 10: Domínio jornalístico

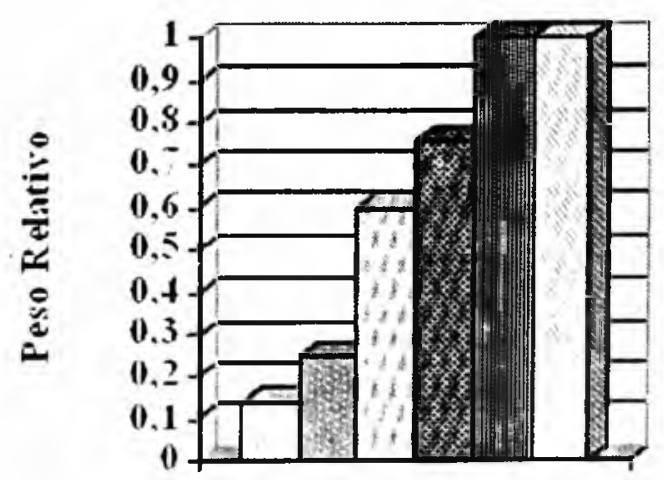

DInfinitiro

$\square$ (ximindo

$\square$ Presente e Pretentos do Indicatro

Imperatiso

国 Futuros do Indicativo

$\square$ Fresente Pret ump e Futuro do subjuntiro

Figura 11: Domínio literário 
De acordo com as Figuras 10 e 11 , verifica-se que, nos dominios jornalístico e literário, os tempos do subjuntivo bem como os futuros do indicativo se constituem como fatores decisivos na aplicação da variante pré-verbal. Ressalte-se que, no contexto dos contos literários, a atuação de tais tempos tem caráter tão proeminente que os registros de próclise se apresentam como categóricos.

No que diz respeito ao imperativo, percebe-se, considerando os dois ambientes analisados, um comportamento discrepante desse modo verbal em termos de condicionamento da variante pré-verbal. Nos textos literários, tal forma se apresenta como favorecedora da próclise, fato não observado nos textos jornalísticos, em que só se registram casos de ênclise.

A propósito das formas nominais do verbo, constatamse suas condições pouco favoráveis à ocorrência da variante pré-verbal em ambos os domínios.

\section{Conclusão}

A análise dos dados permitiu observar, considerando todas as ocorrências verificadas nos corpora, uma distribuição semelhante dos indices gerais das variantes da regra de colocação pronominal nos domínios jornalístico e literário do Português do Brasil.

Averiguou-se, ainda, a depender do contexto morfossintático - em função de o clítico pronominal estar em início absoluto ou nos contextos com elementos proclisadores --, que a ordem preferencial é alterada de forma evidente. Enquanto o início absoluto de oração constitui estrutura altamente favorecedora da variante pós-verbal, os contextos em que se constatam os elementos proclisadores se apresentam como ambientes motivadores da próclise.

No que tange às variáveis extralinguísticas, considerouse a distribuição dos dados consoante os grupos de fatores época de publicação e gêneros textuais. Essa distribuição pro- 
curou demonstrar, apenas, o comportamento da regra de colocação pronominal de acordo com os critérios de constituição do corpus, sugerindo o que constituiria a norma de uso linguistico em textos que se podem considerar representativos da escrita padrão em cada fase.

No inventário de variáveis linguísticas que se mostraram relevantes para a análise do fenômeno variável, tanto no contexto jornalístico quanto no literário, destacaram-se os grupos presença de um possivel elemento proclisador e tempo e modo verbais.

Em decorrência do tratamento especifico das variáveis de ordem linguística, observou-se que, dentre os possiveis elementos proclisadores, os chamados atratores clássicos aqueles considerados tradicionalmente como particulas atratoras - se constituem, de modo geral, nos dois dominios investigados, como ambientes favorecedores da próclise, em oposição às locuções adverbiais, aos SNs sujeitos e às conjunçōes coordenativas, itens desfavorecedores da variante préverbal. As preposições, os operadores de foco e os sintagmas adverbiais de um só vocábulo apresentaram comportamento diferenciado de acordo com o dominio investigado: enquanto as preposiçōes se mostraram desfavorecedoras da variante pré-verbal no contexto jornalístico, os outros elementos apresentaram esse comportamento no contexto literário. A avaliação da variável tempo e modo verbais revelou, como tendência mais evidente, a forte atuação dos tempos do subjuntivo bem como dos futuros do indicativo como contextos favorecedores da próclise, ao contrário das formas nominais do verbo, que se mostraram desfavorecedoras.

Averiguando-se os resultados preliminares deste estudo de natureza variacionista, que descreve a regra variável de colocação pronominal vigente no Português do Brasil. em sua modalidade escrita jornalística e literária, no que respeita a textos do século XX, pretende-se ampliar a investigação por meio do detalhamento dos contextos estruturais presentes em cada gênero textual e em cada fase de publicação. Desse modo, espera-se contribuir para o avanço da pesquisa cientí- 
fica no sentido de estabelecer as regras variáveis que caracterizam o padrão brasileiro escrito.

\section{BiBLIOGRAFIA:}

CUNHA, C.; CINTRA, L. Nova gramática do Português contemporâneo. $3^{a}$ ed. Rio de Janeiro: Nova Fronteira, 2001.

KLAVANS, J. L. The independence of Syntax and Phonology in cliticization. Language 61, p. 95-120. 1985.

LABOV. W. Sociolinguistics patterns. Oxford: Blackwell, 1972.

Principles of linguistics change. Oxford, Cambridge: Blackwell, 1994.

LIMA, R. Gramática normativa da língua portuguesa. $45^{a}$ ed. Rio de Janeiro: José Olympio, 1996.

MOLliCA, M. C. \& BRAGA, M. L. Introdução à Sociolinguistica. São Paulo: Contexto, 2003.

MORICONI, I. (Org.). Os cem melhores contos brasileiros do século. Rio de Janeiro: Editora Objetiva. 2001.

SCHEI. A. A colocaçāo pronominal do português brasileiro: a língua literária contemporânea. Sāo Paulo: Humanitas / FFLCH / USP, 2003.

VIEIRA, S. R. Colocação pronominal nas variedades européia, brasileira e moçambicana: para a definição da natureza do clítico em Português. 2002. Tese (Doutorado em Língua Portuguesa) - Faculdade de Letras, Universidade Federal do Rio de Janeiro, Rio de Janeiro.

WEINREICH, U.; LABOV. W.: HERZOG, M. I. Empirical foundations for theory of linguistic change. In: LEHMANN, W.; MALKIEL, Y. (Ed.). Directions for historical linguistics. Austin: University of Texas Press, 1968. p. 97-195.

ABSTRACT: This investigation aims at determining the status of the order of the clitic pronoun in written Brazilian Portuguese (BP) from the 20 th century. To do so, the contexts of simple verbal forms are investigated since they are an appropriate area to verify the manifestation of atonic pronouns in proclitic and enclitic positions. This study, by means of postulating main constraints for pronominal clitic order in written BP, may contribute to linguistic researches on this theme.

Keywords: Clitic pronoun, Sociolinguistic, variation. 